\title{
Use of a Western blot technique for the serodiagnosis of glanders
}

\author{
Mandy C Elschner ${ }^{1 *}$, Holger C Scholz ${ }^{2}$, Falk Melzer ${ }^{1}$, Muhammad Saqib ${ }^{3,4}$, Peggy Marten ${ }^{1}$, Astrid Rassbach ${ }^{1}$, \\ Michael Dietzsch ${ }^{1}$, Gernot Schmoock ${ }^{1}$, Vania L de Assis Santana ${ }^{5}$, Marcilia MA de Souza ${ }^{5}$, Renate Wernery ${ }^{6}$, \\ Ulrich Wernery ${ }^{6}$, Heinrich Neubauer ${ }^{1}$
}

\begin{abstract}
Background: The in vivo diagnosis of glanders relies on the highly sensitive complement fixation test (CFT). Frequently observed false positive results are troublesome for veterinary authorities and cause financial losses to animal owners. Consequently, there is an urgent need to develop a test with high specificity. Hence, a Western blot assay making use of a partly purified lipopolysaccaride (LPS) containing antigen of three Burkholderia mallei strains was developed. The test was validated investigating a comprehensive set of positive and negative sera obtained from horses and mules from endemic and non endemic areas.
\end{abstract}

Results: The developed Western blot assay showed a markedly higher diagnostic specificity when compared to the prescribed CFT and therefore can be used as a confirmatory test. However, the CFT remains the test of choice for routine testing of glanders due to its high sensitivity, its feasibility using standard laboratory equipment and its worldwide distribution in diagnostic laboratories.

Conclusions: The CFT should be amended by the newly validated Western blot to increase the positive likelihood ratio of glanders serodiagnosis in non endemic areas or areas with low glanders prevalence. Its use for international trade of horses and mules should be implemented by the OIE.

\section{Background}

Glanders, caused by Burkholderia (B.) mallei, is a highly contagious disease in equines which is notifiable to the World Organisation of Animal Health (OIE, Office International des Epizooties). The disease is still endemic in the Middle East, Asia and South America. Recent outbreaks have been reported from Turkey, the United Arabic Emirates, Iraq, Iran, India, Pakistan, Mongolia, China, Brazil and most recently from Bahrain [1-11]. The distribution of glanders in Africa is unknown.

The diagnosis of B. mallei infection still relies on serological proof by agglutination test and complement fixation test (CFT), or proof of the presence of a specific delayed hypersensitivity reaction after intracutaneous application of mallein [12,13]. The CFT for glanders is so far the only officially recognized serological test in

\footnotetext{
* Correspondence: mandy.elschner@fli.bund.de

${ }^{1}$ Friedrich Loeffler Institute, Federal Research Institute for Animal Health Institute of Bacterial Infections and Zoonoses, Naumburger Strasse 96a, 07743 Jena, Germany

Full list of author information is available at the end of the article
}

international trade of equidae. The CFT has a sensitivity of at least 97\% [14] but a notable number of unspecific, false positive results occur [15-18]. False positive results due to cross-reactions may be seen in horses suffering from strangles, equine influenza or petechial fever. The test can also not be applied on sera having so called "anticomplementary activity". In general, serological tests may be negative in emaciated and chronically debilitated animals suffering from glanders [16].

Glanders was eradicated from Western Europe, Australia and North America in the last century applying a rigorous culling of horses found positive in complement fixation and mallein test $[15,19]$. These techniques are useful in eradication programs with regard to specificity and sensitivity [12]. However, in glanders free areas or in areas with very low prevalence of glanders highly specific tests are needed to minimize the number of false positive results [20]. Lipopolysaccharide (LPS) preparations have already been applied in Western blot analysis or competition ELISA to detect anti-B. mallei antibodies in serum of horses [20-22]. But current protocols for 
the extraction and purification of LPS from B. mallei are time consuming, sophisticated and hazardous for the operator $[23,24]$.

Here we describe a new Western blot assay based on an easy to prepare LPS preparation containing antigen from B. mallei, purified from soluble components. With a specificity and a sensitivity of $100 \%$, the assay can be used to confirm positive and at the same time to exclude false positive CFT results.

\section{Methods}

\section{Production of hyperimmune sera in rabbits}

One rabbit was immunized with a crude suspension $\left(10^{6}\right.$ $\mathrm{cfu} / \mathrm{ml}$ ) of heat inactivated B. mallei, B. pseudomallei, B. cepacia, and Pseudomonas aeruginosa, respectively. The strains used are given in Table 1 . The first and second immunizations (days 0 and 3 ) were done by intracutaneous application of 10 doses of $0.2 \mathrm{ml}\left(10^{6} \mathrm{cfu} / \mathrm{ml}\right)$ antigen without adjuvant distributed on the back. Further, 5 immunizations were done by application of $0.5 \mathrm{ml}\left(10^{6} \mathrm{cfu} / \mathrm{ml}\right)$ in the ear vein (days 10, 17, 24, 31, and 38). Seroconversion was monitored by CFT and Western blot assay using the homologous antigen. The final sera were collected 6 weeks after the first immunization (day 42). The animal experiment was authorized by the government of Thuringia, Germany (registration number 04-106/07).

\section{Immunisation of a horse}

To produce a panel of positive control sera, one horse was immunized subcutaneously using a mixture of crude suspensions of heat inactivated $B$. mallei strains Mukteswar, Bogor and Zagreb $\left(10^{9} \mathrm{cfu} / \mathrm{ml}\right)$ adjuvanted with aluminium hydroxide gel (Sigma Chemie $\mathrm{GmbH}$, Munich, Germany). Immunizations were performed weekly for seven weeks with 7 doses of $1.5 \mathrm{ml}$ antigen containing increasing cell concentrations $\left(10^{3} \mathrm{cfu} / \mathrm{ml}\right.$ to $10^{9} \mathrm{cfu} / \mathrm{ml}$ ). The titer was analysed in parallel by CFT and Western blot analysis twice a week and for 10 weeks after the first immunization. The animal experiment was authorized by the government of Thuringia, Germany (registration number 04-105/07).

Table 1 List of bacterial strains used in this study

\begin{tabular}{llll}
\hline Strain & Source & Geographic origin & Species \\
\hline Mukteswar & Horse & India & Burkholderia mallei \\
Bogor & Horse & Indonesia & Burkholderia mallei \\
Zagreb & Horse & Yugoslavia & Burkholderia mallei \\
ATCC 23343 & Human & unknown & Burkholderia pseudomallei \\
DSM 7288 & unknown & unknown & Burkholderia cepacia \\
ATCC 9027 & unknown & unknown & Pseudomonas aeruginosa \\
\hline
\end{tabular}

ATCC: American Type Culture Collection, Manassas, USA. DSM: German Collection of Microorganisms and Cell Cultures, Braunschweig, Germany.

\section{Samples}

A total of 2,282 sera (group I) were collected from different horse populations in several geographical areas of Germany during 2006 to 2009.

These sera were considered negative for glanders because Germany is free of the disease for more than 50 years.

The specificity testing was carried out with 305 samples (group II) randomly selected from group I regarding the Mersenne Twister method by use of the Software SPSS (SPSS Inc., Chicago, USA).

The sensitivity of the Western blot assay was tested using 205 true positive sera (group III). Of these, 171 CFT positive samples were collected from microbiologically or clinically/mallein positive glanderous horses and mules in Punjab, Pakistan $(\mathrm{n}=59)$, Pernambuco, Brazil $(\mathrm{n}=87)$, and Dubai, United Arabic Emirates $(\mathrm{n}=25)$. Included in group III were additionally 21 and 13 sera from the B. mallei-immunized horse and rabbit, respectively.

\section{CFT}

The CFT was performed according to the instructions of the OIE Manual of Diagnostic tests and Vaccines for Terrestrial Animals [13] using a certified, commercially available antigen containing antigen from $B$. mallei strains Bogor, Mukteswar, and Zagreb (cc-pro GmbH, Oberdorla, Germany), and a complement and ready-to use hemolytic system (Institut Virion/Serion GmbH, Würzburg, Germany). Samples were considered negative when $100 \%$ haemolysis occurred at 1:5 dilution, suspicious when $25-75 \%$ haemolysis was seen at dilution 1:5 and positive when no haemolysis was detected at dilution 1:5.

\section{Antigen preparation for the Western blot assay}

B. mallei strains Bogor, Zagreb and Mukteswar were grown on blood agar plates over night at $37^{\circ} \mathrm{C}$ under aerobic conditions. Details on the strains are given in Table 1. For LPS purification, a 10-microliter loop full of bacterial colony material was re-suspended thoroughly in $6 \mathrm{ml}$ saline $(0.9 \% \mathrm{NaCl}, \mathrm{pH} 7.0)$ up to a density comparable to McFarland scale 4.0. A volume of 3 $\mathrm{ml}$ of $37 \%$ formaldehyde was added to achieve a final formaldehyde concentration of $12.3 \%$. The suspension was rigorously vortexed and subsequently swayed using an orbital shaker (Polymax 1040, Heidolph Instruments $\mathrm{GmbH}$, Schwabach, Germany) over night at room temperature. Controls for sterility confirmed inactivation of bacteria. Cells were pelletized by centrifugation at 3.500 $\times \mathrm{g}$ for $15 \mathrm{~min}$ and the supernatant was discarded. Soluble components were removed by 3 consecutive centrifugation and washing steps with $9 \mathrm{ml}$ phosphate buffered saline (PBS, pH 7.0) shaking at $15 \mathrm{rpm}$ for 10 minutes. The LPS-containing pellet was re-suspended in 
$9 \mathrm{ml}$ PBS. Two further extraction steps by adding 1 volume of $37 \%$ formaldehyde into 2 volume re- suspended cells in PBS were applied. By 3 consecutive washing steps with PBS the soluble cell components and the formaldehyde were removed. After the last washing step the pellet was resuspended in PBS. Aliquots were directly used for SDS-polyacrylamide gel electrophoresis (SDS-PAGE) and subsequent Western blot analysis. The washing steps and the number of bacteria used for LPS preparation were crucial for the efficient removal of soluble components from the LPS-containing cell debris. Optimal purification was achieved using $9 \times 10^{8}$ cells $/ \mathrm{ml}$ (McFarland scale 3) or less (data not shown).

The correct formation of a typical LPS ladder was proofed by SDS-PAGE and silver staining before blotting. For SDS-PAGE several dilutions from the prepared LPS containing cell suspension in Laemmli Buffer (Sigma, Munich, Germany) were loaded on a precast denaturating 4-12\% polyacrylamide gradient gel (Invitrogen, Karlsruhe, Germany) and separated at a constant voltage of $200 \mathrm{~V}$ for 50 min using the Xcell SureLock ${ }^{\mathrm{TM}}$ MiniCell (Invitrogen). Silver staining was carried out with the SilverQuest ${ }^{\mathrm{TM}}$ silver staining kit (Invitrogen). The LPS extracted from each of the $B$. mallei strains showed the typical LPS ladder with no visible differences. We believe that soluble antigens are mainly removed from the preparation but we are well aware, that our antigen is not pure and contains other components, like high molecular weight components (Figure 1). The protein content of each antigen preparation was below $0.5 \mathrm{mg} / \mathrm{ml}$, measured by absorption at $280 \mathrm{~nm}$ (Spectrophotometer NanoDrop 1000, Thermo Fisher Scientific, Bonn, Germany). For further use, the antigen preparations of the $B$. mallei strains Bogor, Zagreb and Mukteswar were mixed equally.

\section{Immuno blotting}

For Western blotting analysis, $350 \mu \mathrm{l}$ LPS-containing suspension of B. mallei strains Bogor, Zagreb and Mukteswar were separated on a precast preparative $4-12 \%$ polyacrylamide gradient gel (Invitrogen) as described above. LPS was transferred to a $0.45 \mu \mathrm{m}$ nitrocellulose membrane (Invitrogen) by blotting at constant $30 \mathrm{~V}$ for $1 \mathrm{~h}$ using the Novex ${ }^{\circledR}$ Blot Module (Invitrogen). The membrane was blocked overnight in Blocking Solution (Candor Bioscience, Weißensberg, Germany). After three washing steps the membrane was cut into strips of $3 \mathrm{~mm}$ and stored at $-20^{\circ}$ $\mathrm{C}$ or was used for subsequent immunoblot analysis. Stripes were incubated with equine or rabbit sera in a 1:50 dilution in Low Cross Buffer (Candor Bioscience) for $1.5 \mathrm{~h}$ at room temperature followed by three washing steps in washing buffer (Candor Bioscience) $20 \mathrm{~min}$ each. The strips were then incubated for $1.5 \mathrm{~h}$ at room temperature in Low Cross Buffer containing alkaline phosphatase-

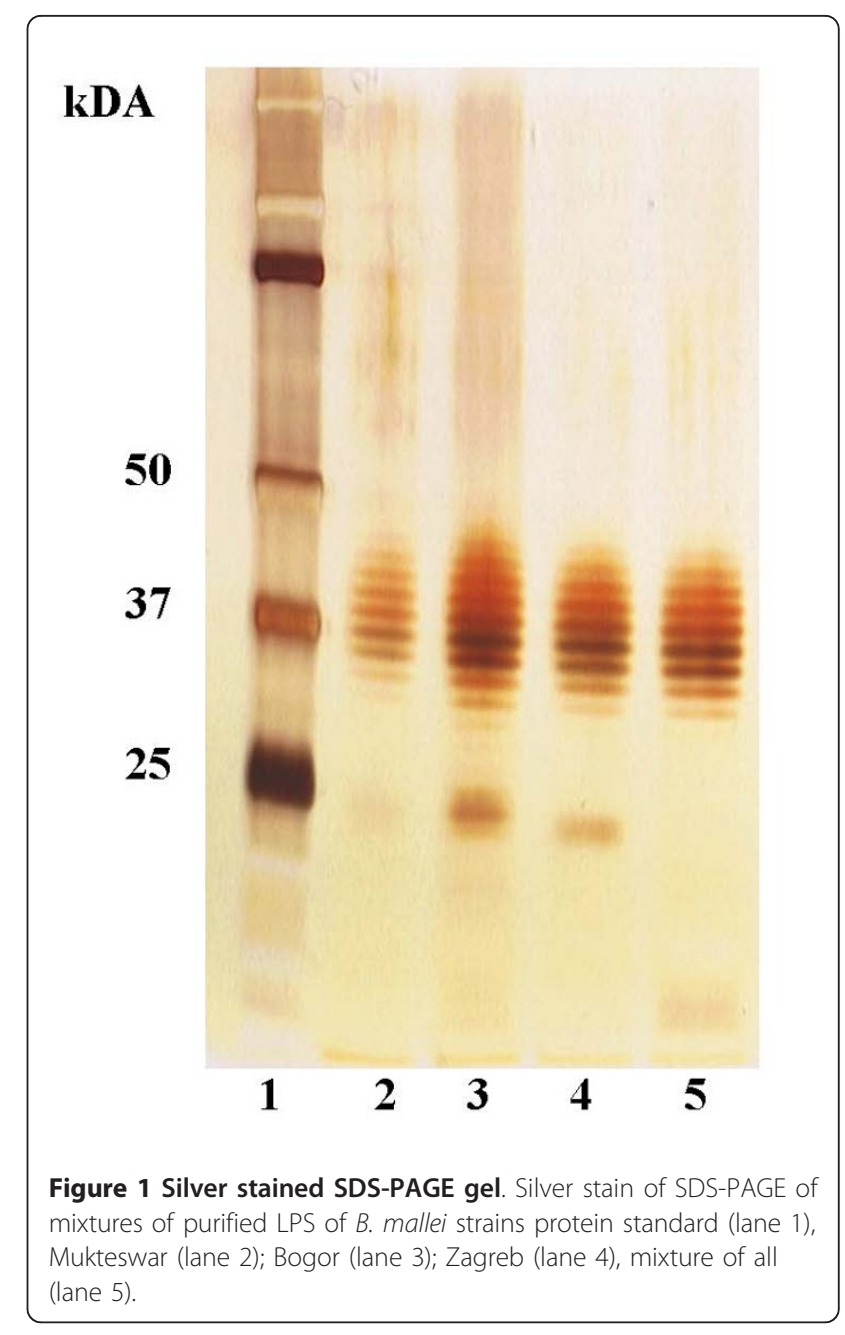

conjugated rabbit anti-horse-IgG or goat anti-rabbit-IgG (Sigma, Munich, Germany, 1:5,000). After three additional washing steps, the strips were stained with NBT-BCIP ${ }^{\circledR}$ solution (Sigma). The immunostaining was stopped by washing with distilled water after 10 minutes. The immunoblot was scored positive if the banding pattern of the $B$. mallei LPS ladder within the region of 20 to $60 \mathrm{kDa}$ was clearly visible, scored suspicious if a weak color reaction was detected, and scored negative if no reaction was seen (Figure 2).

\section{Results \\ CFT}

All 205 samples of group III were positive resulting in a sensitivity of $100 \%$. Seventy of the 1,282 sera of group I showed a false positive or suspicious CFT result resulting in a specificity of $94.5 \%$.

\section{Western blot assay}

All 305 samples of group II were tested negative and all of 205 positive samples (group III) showed a clearly 


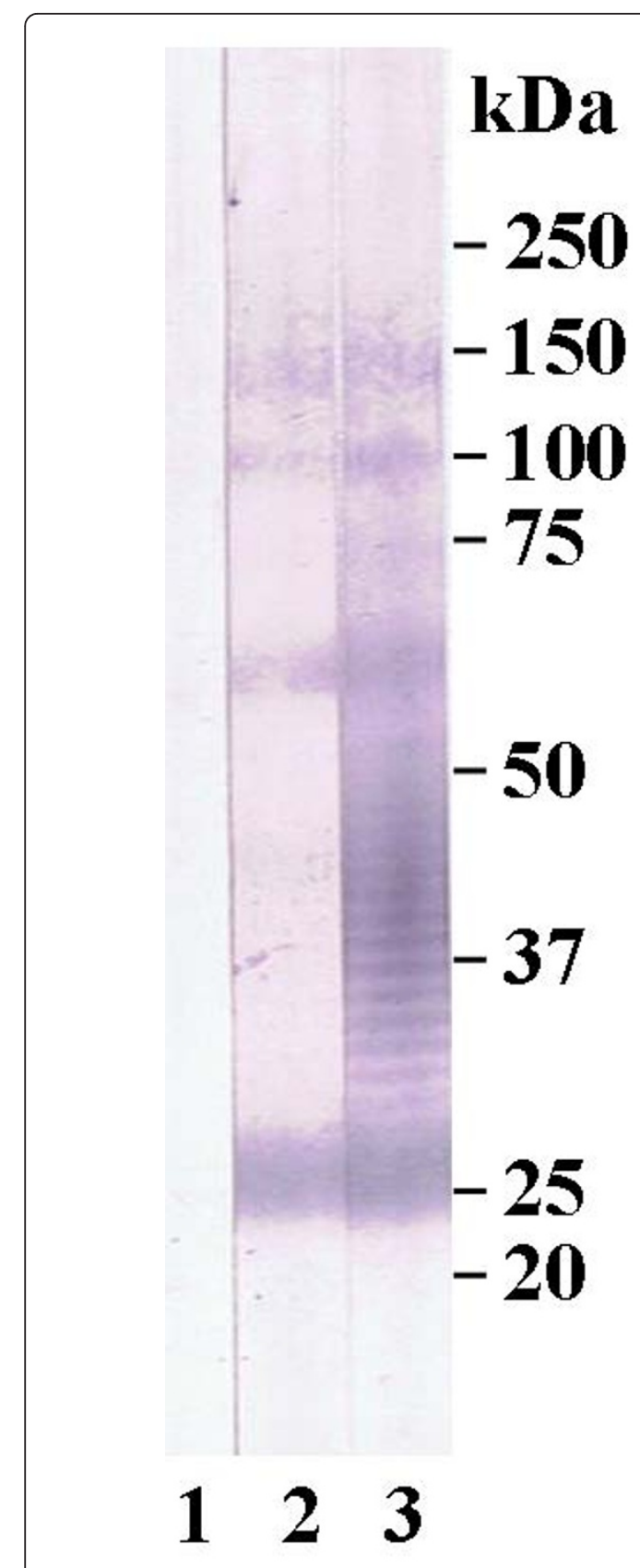

Figure 2 Score of immunoblot. Score of immunoblot: lane 1: negative, lane 2: suspicious, lane 3: positive.

visible LPS banding pattern and were scored positive. A panel of immunoblot strips of samples from Pakistan are shown in Figure 3. On this basis, the diagnostic sensitivity and specificity of the Western blot was calculated to be $100 \%$. CFT false positive samples $(n=70)$ from group I were also tested negative.

Rabbit hyperimmune sera against B. cepacia and $P$. aeruginosa showed no clearly visible LPS banding pattern. Only the anti- B. pseudomallei serum cross

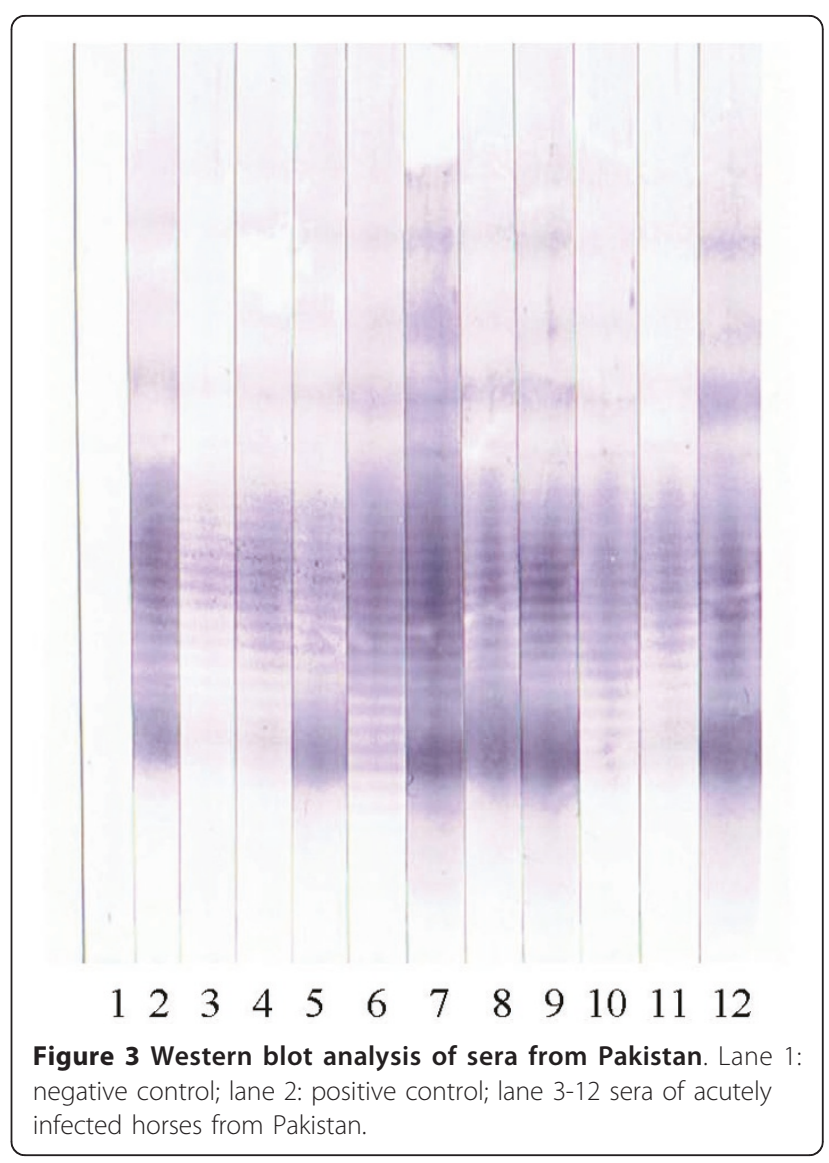

reacted with the $B$. mallei antigen in the Western blot assay (Figure 4).

\section{Discussion}

Following eradication of glanders from the Western hemisphere, false positive CFT results pose a considerable problem in trade of equids. The need for the development and evaluation of highly specific serological tests for exclusion of false positive results became imperative. One competitive ELISA (cELISA) was described based on mallein as antigen and an in house monoclonal antibody (mAb) [22]. Another cELISA used a commercially available $B$. mallei specific mAb (3D11) and a simple carbohydrate preparation of $B$. mallei as antigen [20]. Both tests show comparable sensitivity (98.9\% and $98.6 \%$, respectively) and a specificity of $100 \%$. Due to the sophisticated technique, the high costs for mallein and mAbs and the restricted availability of these mAbs, the cELISAs will not be available for routine laboratories in the future. Other tests still used for diagnosing glanders are Rose Bengal agglutination test, indirect hemagglutination test, counter immunoelectrophoresis and indirect fluorescent antibody test [21,25-29] which have either technical shortcomings or have low specificity and/or sensitivity. New approaches 


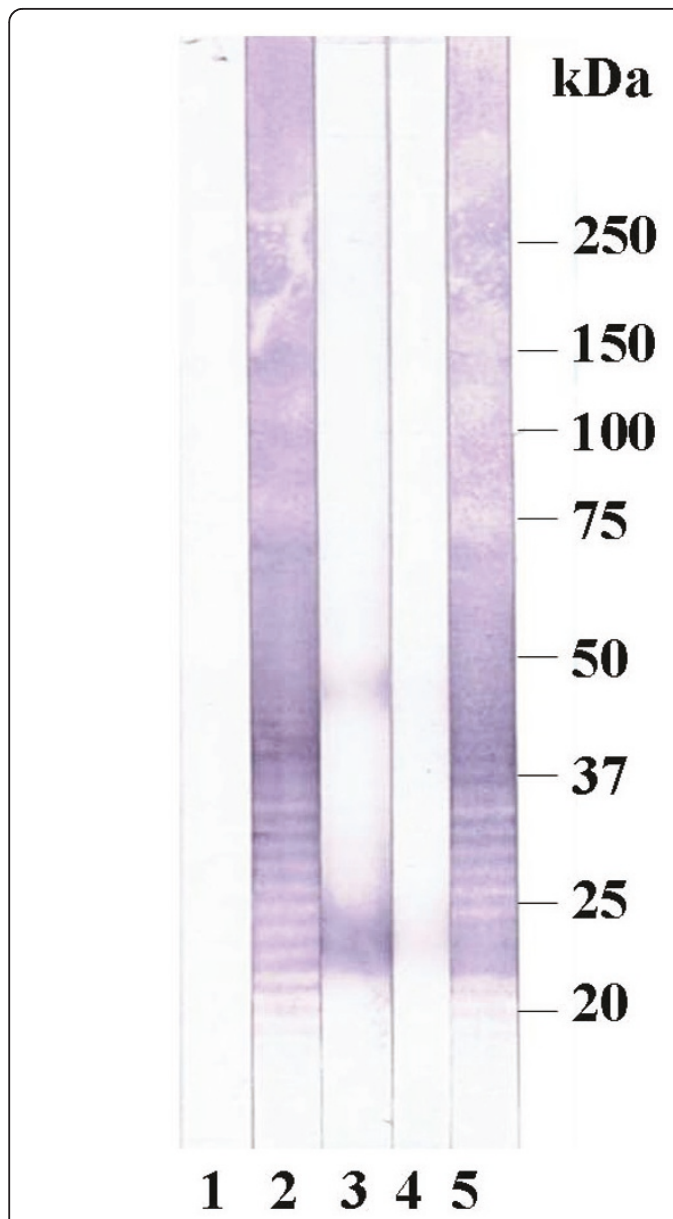

Figure 4 Western blot analysis of rabbit hyperimmunesera (HIS) against $\boldsymbol{B}$. mallei LPS. Lane 1: negative control serum, lane 2: anti B. mallei HIS, lane 3: anti B. cepacia HIS, lane 4: anti $P$. aeruginosa HIS, lane 5: anti B. pseudomallei HIS.

using microarray technology for the serodiagnosis of glanders and melioidosis are based on polysaccharide antigens [30] but these techniques are expensive and not suited for routine mass testing of sera.

The CFT is used for diagnosis of many diseases worldwide and has a high sensitivity, especially when used for glanders serodiagnosis. This finding was again demonstrated by our study. We conclude therefore that the CFT is still the most valuable screening test currently available. But again, the CFT had a specificity of only $94.5 \%$ in a set of horse sera from a glanders free region (Germany). Consequently, a considerable number of CFT false positive tested animals must be expected when horses from glanders free regions are tested by the current OIE standards [6]. The need of the development of a supplementary confirmatory test with a high negative likelihood ratio for international trade was stressed again.
B. mallei LPS-based Western blot assays are cheap, easy to produce and user friendly test systems which have been developed in the past, but could not be evaluated on a significant number of positive and negative horse sera until now [12]. We were able to collect 205 sera of infected animals from geographically different regions and a set of sera from immunized animals (horse and rabbit), enabling us to validate the Western blot assay for its use in the routine serodiagnosis of glanders.

It was proven that the Western blot technique is highly specific and is able to supplement the CFT to avoid false positive diagnoses in horses and mules. The advance of the immunoblot technique is that specific bands can be distinguished from background reactions in contrast to the CFT. The investigation of the hyperimmune sera of rabbits against $B$. mallei LPS showed that $B$. cepacia and $P$. aeruginosa won't interfere with this technique. B. pseudomallei antibodies, however, will cause false positive results due to known cross-reacting epitopes of the LPS [31,32]. In international trade, it is also of utmost importance not to transport animals infected with the dangerous zoonotic agent B. pseudomallei from endemic areas to areas with ambient environment where B. pseudomallei could establish a temporal or permanent reservoir. An identification and destruction of those animals will have an additional zoosanitary and ecological benefit.

\section{Conclusions}

The developed method of LPS-preparation reported here is highly feasible and cheap. The qualitative and quantitative composition of our antigen proofed to be suitable for its use in immunobloting. The developed method is a highly sensitive and specific serological test for glanders diagnosis. It will be of great value in glanders endemic areas in less developed countries.

\section{Abbreviations}

CFT: complement fixation test; LPS: lipopolysaccaride; OIE: Office International des Epizooties (World organisation for animal health); Cfu: colony forming units; PBS: phosphate buffered saline; SDS-PAGE: sodium dodecylsulfate polyacrylamide gel electrophoresis; mAb: monoclonal antibody; cELISA: competitive enzyme linked immunosorbent assay; ATCC: American Type Culture Collection; DSM: German Collection of Microorganisms and Cell Cultures

\section{Acknowledgements}

We are grateful to C. Lodri and U. Pfeil for excellent technical assistance and to Dr. W. Herbst (Justus-Liebig-University Gießen) for providing collection of horse sera fom Germany.

\section{Author details}

${ }^{1}$ Friedrich Loeffler Institute, Federal Research Institute for Animal Health, Institute of Bacterial Infections and Zoonoses, Naumburger Strasse 96a, 07743 Jena, Germany. ${ }^{2}$ Bundeswehr Institute of Microbiology, Neuherbergstrasse 11, 80937 Munich, Germany. ${ }^{3}$ Veterinary Research Centre, PO Box 50 Seeb, Postal Code 121, Sultanate of Oman. ${ }^{4}$ Department of 
Clinical Medicine and Surgery, University of Agriculture, Faisalabad 38040, Pakistan. ${ }^{5}$ Laboratório Nacional Agropecuário, Ministério Da Agricultura, Rua Dom Manoel De Medeiros, S/N Dois Irmãos Recife PE Brasil CEP 52171-030, Brazil. ${ }^{6}$ Central Veterinary Research Institute, Dubai PO Box 597, United Arabic Emirates.

\section{Authors' contributions}

MCE designed the study, coordinated the investigation of all samples by CFT and western blot assay, evaluated and interpreted the data and wrote the manuscript.

HN has the supervision of the research group, contributed to acquisition of funding, co-design of the study and was involved in the drafting of the manuscript.

HCS, HN established the antigen purification procedure and westernblot assay.

UW, RW, MS, VLAS, MMAS have been involved in malleinisation and health monitoring of the horses, collection and pre-testing and providing of samples including the interpretation of results.

PM established, standardized and performed the western blot assay. $F M, A R, M D, G S$ have been involved in the design of the study, providing and supporting laboratory work and discussion of results including drafting the manuscript.

All authors revised the manuscript critically and approved the final version.

Received: 9 August 2010 Accepted: 19 January 2011

Published: 19 January 2011

\section{References}

1. Bazargani TT, Tadjbakhs H, Badii A, Zahraei T: The outbreak of glanders in some racehorses in three states of Iran. J Eq Vet Sci 1996, 16:232-236.

2. Al-Ani FK, Al-Rawashdeh OF, Ali AH, Hassan FK: Glanders in horses clinical, biochemical and serological studies in Iraq. Vet Arhiv 1998, 68:155-162.

3. Muhammad G, Khan MZ, Athar M: Clinico-microbiological and therapeutic aspects of glanders in equines. J Equine Sci 1998, 9:93-96.

4. Arun S, Neubauer H, Gurel A, Ayyidiz G, Kuscu B, Yesidere T, Meyer H, Hermanns W: Equine glanders in Turkey. Vet Rec 1999, 144:255-258.

5. Mota RA, Brito MF, Castro FJ, Massa M: Glanders in horses and mules of the states of Pernambuco and Alagoas, Brazil. Pes Vet Bras 2000, 20:155-159.

6. Wernery $U$, Zachariah $R$, Wernery $R$, Joseph $S$, Valsini L: Ten years of freedom from notifiable equine diseases in the United Arab Emirates. In Proceedings of the 15th International Conference of Racing Analysts and Veterinarians 2005; Dubai, United Arab Emirate. Edited by: Albert PH, Morton T, Wade JF. R 2005:1-4.

7. Odontsetseg $\mathrm{N}$, Mweene AS, Kida $\mathrm{H}$ : Viral and bacterial diseases in livestock in Mongolia. Jpn J Vet Res 2005, 52:151-162.

8. Malik P, Khurana SK, Singh BK, Dwivedi SK: Recent outbreak of glanders in India. Ind J Animal Science 2009, 79:1015-1017.

9. Elschner MC, Klaus CU, Liebler-Tenorio E, Schmoock G, Wohlsein P, Tinschmann O, Lange E, Kaden V, Klopfleisch R, Melzer F, Rassbach A, Neubauer $\mathrm{H}$ : Burkholderia mallei infection in a horse imported from Brazil. Equine vet Educ 2009, 21:147-150.

10. Naureen A, Saqib M, Muhammad F, Ahmad R, Muhammad G, Asi MN, Hussain MH, Lodhi LA, Khan MS, Thibault FM: Antimicrobial susceptibility of 41 Burkholderia mallei isolates from spontaneous outbreaks of equine glanders in Punjab, Pakistan. J Eq Vet Sci 2010, 30:134-141.

11. OIE-WAHID, World Animal Health Information Database Interface of OIE, online version. [http://www.oie.int].

12. Neubauer $H$, Sprague LD, Zacharia R, Tomaso H, Al Dahouk S, Wernery $R$, Wernery U, Scholz HC: Serodiagnosis of Burkholderia mallei infections in horses: state-of-the-art and perspectives. J Vet Med B Infec Dis Vet Public Health 2005, 52:201-205.

13. OIE: Glanders. 2008, Chapter 2.5.11: [http://www.oie.int], online version

14. Cravitz L, Miller WR: Immunological studies with Malleomyces mallei and Malleomyces pseudomallei. II. Agglutination and complement fixation tests in man and laboratory animals. J Infect Dis 1950, 86:52-62.

15. Manninger R: Rotzkrankheit. Malleus. In Spezielle Pathologie und Therapie der Haustiere. Volume 1. 9 edition. Edited by: Marek J, Manninger R, Mocsy J. Jena: Gustav Fischer; 1945:591-627.
16. Wilson GS, Miles AA: Glanders and Melioidosis. In Topley and Wilson's Principles of Bacteriology and Immunity. 3 edition. Edited by: Wilson GS, Miles AA. London: Edward Arnold 1946:1413.

17. Misra VC, Arora AK: Serological cross-reactions between Pseudomonas mallei and some other bacteria. Ind I Comp Microbiol Immunol Infect Dis 1990, 11:28-31.

18. Turnbull A, Wernery U, Wernery R, Anandh JP, Kinne J: Survey of six infectious diseases of feral donkeys in United Arab Emirates. Eq Vet $J$ 2002, 14:33-38.

19. Derbyshire JB: Eradication of glanders in Canada. Can Vet J 2002, 43:722-726.

20. Sprague LD, Zachariah R, Neubauer H, Wernery R, Joseph M, Scholz HC, Wernery U: Prevalence-dependent use of serological tests for diagnosing glanders in horses. BMC Vet Res 2009, 5:32.

21. Katz J, Chieves LP, Hennager SG, Nicholson J, Fisher TA, Byers PE: Serodiagnosis of equine piroplasmosis, dourine, and glanders using an arrayed immunoblotting method. J Vet Diagn Invest 1999, 11:292-294.

22. Katz J, Dewald R, Nicholson J: Procedurally similar competitive immunoassay systems for the serodiagnosis of Babesia equi, Babesia caballi, Trypanosoma equiperdumand Burkholderia mallei infection in horses. J Vet Diagn Invest 2000, 12:46-50.

23. Anuntagool N, Sirisinha S: Antigenic relatedness between Burkholderia pseudomallei and Burkholderia mallei. Microbiol Immunol 2002, 46:143-150.

24. Pitt TL, Aucken H, Dance DA: Homogeneity of lipopolysaccharide antigens in Pseudomonas pseudomallei. J Infect 1992, 25:139-146.

25. Naureen A, Saqib M, Muhammad G, Hussain MH, Asi MN: Comparative evaluation of Rose Bengal plate agglutination test, mallein and some conventional serological tests for diagnosis of spontaneous equine glanders. J Vet Diag Invest 2007, 19:362-367.

26. Misra VC, Arora AK: Diagnosis of glanders by counter-immunoelectrophoresis test and its efficacy vis-a-vis other test. J Remount Vet Corps 1988-185.

27. Jana AM, Gupta AK, Pandya G, Verma RD, Rao KM: Rapid diagnosis of glanders in equines by counter-immuno-electrophoresis. Ind Vet J 1982, 59:5-9.

28. $M a C L$, Fan $S M$, Wang $X$, Jiang L, Fang SQ: Diagnosis of glanders in horses by the indirect fluorescent antibody (IFA) technique. Chinese J Vet Sci Technol 1986, 9:3-5.

29. Zhang WD, Lu ZB: Application of an indirect haemagglutination test for the diagnosis of glanders and melioidiosis. Chinese J Vet Med 1983, 9:8-9.

30. Parthasarathy N, DeShazer D, England M, Waag DM: Polysaccharide microarray technology for the detection of Burkholderia pseudomallei and Burkholderia mallei antibodies. Diag Microbio Infect Dis 2006, 56:329-332.

31. Brett PJ, Woods DE: Structural and immunological characterization of Burkholderia pseudomallei O-polysaccharide-flagellin protein conjugates. Infect Immun 1996, 64:2824-2828.

32. Burtnick MN, Brett PJ, Woods DE: Molecular and physical characterization of Burkholderia mallei O antigens. J Bacteriol 2002, 84:849-852.

doi:10.1186/1746-6148-7-4

Cite this article as: Elschner et al:: Use of a Western blot technique for the serodiagnosis of glanders. BMC Veterinary Research 2011 7:4.

\section{Submit your next manuscript to BioMed Central and take full advantage of:}

- Convenient online submission

- Thorough peer review

- No space constraints or color figure charges

- Immediate publication on acceptance

- Inclusion in PubMed, CAS, Scopus and Google Scholar

- Research which is freely available for redistribution 